\title{
Article
}

\section{Urinary PGE-M in Men with Prostate Cancer}

\author{
Maeve Kiely ${ }^{1}$, Ginger L. Milne ${ }^{2}$, Tsion Z. Minas ${ }^{1}$, Tiffany H. Dorsey ${ }^{1}$, Wei Tang ${ }^{1}$, Cheryl J. Smith ${ }^{1}$, \\ Francine Baker ${ }^{1}{ }^{(}$, , Christopher A. Loffredo ${ }^{3}$, Clayton Yates ${ }^{4}\left(\mathbb{D}\right.$, Michael B. Cook ${ }^{5}$ and Stefan Ambs ${ }^{1, * \mathbb{D}}$
}

1 Laboratory of Human Carcinogenesis, Center for Cancer Research, National Cancer Institute, National Institutes of Health, Bethesda, MD 20892, USA; maeve.bailey-whyte@nih.gov (M.K.); tsion.minas@nih.gov (T.Z.M.); howet@mail.nih.gov (T.H.D.); tangw3@mail.nih.gov (W.T.); cheryl.smith2@nih.gov (C.J.S.); francine.baker@nih.gov (F.B.)

2 Division of Clinical Pharmacology, Department of Medicine, Vanderbilt University Medical Center, Nashville, TN 37232, USA; ginger.milne@vumc.org

3 Cancer Prevention and Control Program, Lombardi Comprehensive Cancer Center, Georgetown University Medical Center, Washington, DC 20007, USA; cal9@georgetown.edu

4 Center for Cancer Research, Department of Biology, Tuskegee University, Tuskegee, AL 36088, USA; cyates@tuskegee.edu

5 Division of Cancer Epidemiology and Genetics, National Cancer Institute, National Institutes of Health, Bethesda, MD 20850, USA; cookmich@mail.nih.gov

* Correspondence: ambss@mail.nih.gov

Citation: Kiely, M.; Milne, G.L.; Minas, T.Z.; Dorsey, T.H.; Tang, W.; Smith, C.J.; Baker, F.; Loffredo, C.A.; Yates, C.; Cook, M.B.; et al. Urinary PGE-M in Men with Prostate Cancer. Cancers 2021, 13, 4073. https://doi.org/10.3390/cancers 13164073

Academic Editor: Mary F McMullin

Received: 8 July 2021

Accepted: 10 August 2021

Published: 13 August 2021

Publisher's Note: MDPI stays neutral with regard to jurisdictional claims in published maps and institutional affiliations.

Copyright: (c) 2021 by the authors. Licensee MDPI, Basel, Switzerland This article is an open access article distributed under the terms and conditions of the Creative Commons Attribution (CC BY) license (https:// creativecommons.org/licenses/by/ $4.0 /)$.
Simple Summary: Elevated levels of urinary prostaglandin E metabolite (PGE-M), a marker of inflammation, have previously been associated with cancer incidence and metastasis. Studies investigating PGE-M in prostate cancer are lacking even though chronic inflammation is a candidate risk factor for the disease. We investigated the association of PGE-M with lethal prostate cancer. We measured PGE-M in the urine of men with prostate cancer and in men without prostate cancer (population controls). Our participants included African American and European American men. Because African American men die more frequently from prostate cancer than European American men, we investigated whether high PGE-M may contribute to the increased mortality among African American prostate cancer patients. We did not observe a relationship between PGE-M and prostate cancer aggressiveness or prostate cancer-specific mortality in our study population, neither in the combined cohort nor in the race/ethnicity stratified analysis. Interestingly, however, we observed a significant relationship between high PGE-M and all-cause mortality in African American men with prostate cancer. Yet, there was no association between high PGE-M and all-cause mortality when these men were regular aspirin users.

Abstract: Urinary PGE-M is a stable metabolite of prostaglandin E2 (PGE2). PGE2 is a product of the inflammatory COX signaling pathway and has been associated with cancer incidence and metastasis. Its synthesis can be inhibited by aspirin. We investigated the association of PGE-M with lethal prostate cancer in a case-control study of African American (AA) and European American men. We measured urinary PGE-M using mass-spectrometry. Samples were obtained from 977 cases and 1022 controls at the time of recruitment. We applied multivariable logistic and Cox regression modeling to examine associations of PGE-M with prostate cancer and participant survival. Median survival follow-up was 8.4 years, with 246 deaths among cases. Self-reported aspirin use over the past 5 years was assessed with a questionnaire. Race/ethnicity was self-reported. Urinary PGE-M levels did not differ between men with prostate cancer and population-based controls. We observed no association between PGE-M and aggressive disease nor prostate-cancer-specific survival. However, we observed a statistically significant association between higher (>median) PGE-M and all-cause mortality in AA cases who did not regularly use aspirin ( $\mathrm{HR}=2.04,95 \% \mathrm{CI} 1.23-3.37)$. Among cases who reported using aspirin, there was no association. Our study does not support a meaningful association between urinary PGE-M and prostate cancer. Moreover, PGE-M levels were not associated with aggressive prostate cancer. However, the observed association between elevated PGE-M and all-cause mortality in AA non-aspirin users reinforces the potential benefit of aspirin to reduce mortality among AA men with prostate cancer. 
Keywords: prostate cancer; aspirin; health disparity; prostaglandin E metabolite; cyclooxygenase; inflammation

\section{Introduction}

Chronic inflammation has been implicated in prostate cancer etiology and progression [1-3]. The pro-inflammatory cyclooxygenase (COX) pathway, where arachidonic acid is converted to bioactive prostaglandins and eicosanoids via the COX-1 and COX-2 enzymes, is linked to elevated systemic inflammation [4]. Upregulated expression of the COX-2 enzyme in cancer cells has been associated with metastatic prostate cancer [5-7], but the clinical significance of COX-2 inhibition for the treatment of prostate cancer remains uncertain [8].

Prostaglandin E2 (PGE2) is the most abundant prostaglandin synthesized by the COX pathway. In colon cancer, this prostaglandin is the key mediator of the oncogenic effects of COX-2 [9]. PGE2 promotes cancer cell survival and metastasis through stem cell expansion and inhibition of the p53 pathway in colorectal cancer [10,11]. Endogenous PGE2 production can be estimated by measuring its major metabolite, urinary PGE-M (11 $\alpha$-hydroxy-9,15-dioxo-2,3,4,5-tetranor-prostane-1,20-dioic acid) [12,13]. Elevated PGE-M has been associated with a risk of cancer in many sites, including colorectal cancer [14], postmenopausal breast cancer [15], pancreatic cancer [16], and gastric cancer [17]. This pattern is not universally described, however, and a null association has been reported for ovarian cancer [18]. Additionally, the use of the COX-2-specific inhibitor, celecoxib, did not improve survival in prostate cancer, as reported in the STAMPEDE trial [8]. Elevated PGE-M has been associated with metastasis of breast cancer to the lung [4] and colorectal metastasis in mouse models $[10,14]$. To date, there has been a lack of studies investigating the relationship between PGE-M and prostate cancer despite strong rationale, with chronic inflammation being linked to the disease as a candidate risk factor [2,19].

The anti-inflammatory drug aspirin is now recommended by the US Preventative Services Task Force for the prevention of colorectal cancer [20,21]. Aspirin can inhibit PGE-M levels, and the ASPIRED trial reports utility for measuring urinary PGE-M as a biomarker of aspirin effectiveness in the prevention of disease recurrence [22]. Aspirin has also shown chemopreventive effects against aggressive prostate cancer in high-risk populations $[23,24]$ and lethal prostate cancer in general $[25,26]$.

With strong prior evidence suggesting inflammation as a risk factor of aggressive prostate cancer, this study aimed to identify if elevated urinary PGE-M levels are associated with adverse survival outcomes in men with prostate cancer. Furthermore, we aimed to identify if aspirin use may influence these survival outcomes.

\section{Materials and Methods}

\subsection{Study Population}

The NCI-Maryland prostate cancer case-control study has been previously described $[24,27]$. The study was initiated to test the primary hypothesis that environmental exposures and ancestry-related factors contribute to the excessive prostate cancer burden among African American (AA) men. Prior to interview, all subjects signed informed consent for participation. All study forms and procedures were approved by the NCI (protocol \#05-C-N021) and the University of Maryland (protocol \#0298229) Institutional Review Boards. Research followed the ethical guidelines set by the Declaration of Helsinki. Cases were recruited at the Baltimore Veterans Affairs Medical Center and the University of Maryland Medical Center through arrangements with physicians. Controls were identified through the Maryland Department of Motor Vehicle Administration database and were frequency-matched to cases on age and race. This article follows the STROBE guidelines for the reporting of observational studies. See Supplementary Methods for exclusion/inclusion criteria, questionnaire, and biospecimen information. 


\subsection{Laboratory Assay for Urinary PGE-M Measurement}

Urinary 11a-hydroxy-9,15-dioxo-2,3,4,5-tetranor-prostane-1,20-dioic acid (PGE-M) was measured by the Eicosanoid Core Laboratory at Vanderbilt University Medical Center (Nashville, TN, USA). See Supplementary Methods for more details about this assay and its quality control performance. Measurement of urinary PGE-M has been established as a reliable reflection of circulating prostaglandin E2 [28].

\subsection{Assessment of Aspirin Use}

Our survey evaluated aspirin use with the following question: "Have you taken aspirin or aspirin-containing compounds (such as Bufferin, Anacin, Ascriptin, Excederin) regularly-at least one pill per week for 2 months during the past 5 years", with responses no, yes, or do not know.

\subsection{Statistical Analysis}

Data analysis was performed using the Stata/SE 16.0 statistical software package (StataCorp). All statistical tests were two-sided. An association was considered statistically significant with $p<0.05$. For analysis, we assessed PGE-M as either a continuous measure or assigned PGE-M values to quartiles (Q1-Q4, Q1 being the lowest, Q4 being the highest) and median $(\leq$ median/>median) with cutoff points determined using the distribution of PGE-M values among all controls. PGE-M data analyzed as a continuous measure were $\log 2$ transformed. The non-parametric Mann-Whitney test was used to determine differences in PGE-M levels across cases and controls. Furthermore, cases were assigned to risk groups according to National Comprehensive Cancer Network (NCCN) Risk Score classification, which stratifies patients into pretreatment recurrence risk groups according to the clinical tumor stage, biopsy Gleason score, and serum prostate-specific antigen level [29]. We condensed these risk groups into 4 categories (low, intermediate, high/very high, and regional/metastatic).

Unconditional logistic regression models were used to calculate adjusted odds ratios (OR) and 95\% confidence intervals (CI) to assess the association of PGE-M with either use of aspirin in cases and controls, case status, or the NCCN risk score in cases. We adjusted for the following potential confounding factors: age at study entry, body mass index (BMI), diabetes, aspirin use, education, family history of prostate cancer, self-reported race, smoking history, treatment, disease stage, and Gleason score (see Supplementary Methods for more information). To test for heterogeneity of odds ratios, we applied the Breslow-Day test. To test for statistical interactions, we applied the multivariable logistic regression model with and without the interaction term and examined significance with the likelihood ratio test. A $p<0.05$ was considered as statistical evidence for effect modification.

We applied the Cox regression model to estimate adjusted hazard ratios (HR) and $95 \%$ confidence intervals $(\mathrm{CI})$ for all-cause mortality and prostate cancer-specific mortality. Median survival follow-up for cases was 8.4 years. In the analysis of all-cause mortality, median follow-up time to death from any cause was 4.52 years for AA men and 5.99 years for European American (EA) men. In the analysis of prostate cancer-specific survival, median follow-up time to death from prostate cancer was 2.75 years for AA men and 7.7 years for EA men. We adjusted for potential confounding factors (defined in Supplementary Methods). We calculated survival for cases from date of diagnosis to either date of death or to the censor date of 31 December 2018. We confirmed non-violation of the proportionality assumption based on the goodness-of-fit test using Schoenfeld residuals. For survival analysis with the Kaplan-Meier method, the log-rank test was used to examine differences in all-cause and prostate cancer-specific mortality according to PGE-M levels. 


\section{Results}

3.1. Clinical and Demographic Characteristics of Participants in the NCI-Maryland (NCI-MD) Prostate Cancer Case-Control Study

Demographic characteristics of the enrolled subjects are shown in Table S1, together with the disease characteristics of the cases. The study enrolled 977 cases (490 AA and $487 \mathrm{EA}$ ) and 1022 population controls (479 AA and $543 \mathrm{EA}$ ) from the greater Baltimore area in Maryland. Race/ethnicity was self-reported as part of the eligibility screener and within the questionnaire.

\subsection{Urinary PGE-M Levels Do Not Differ between Men with Prostate Cancer and Population-Based Controls}

We measured urinary PGE-M in samples that were obtained from 975 cases and 1020 controls at time of recruitment. We then investigated whether urinary PGE-M differed between men with and without prostate cancer. Stratified by self-reported race, we did not observe consistent differences between cases and controls for the AA and EA men (Figure 1).

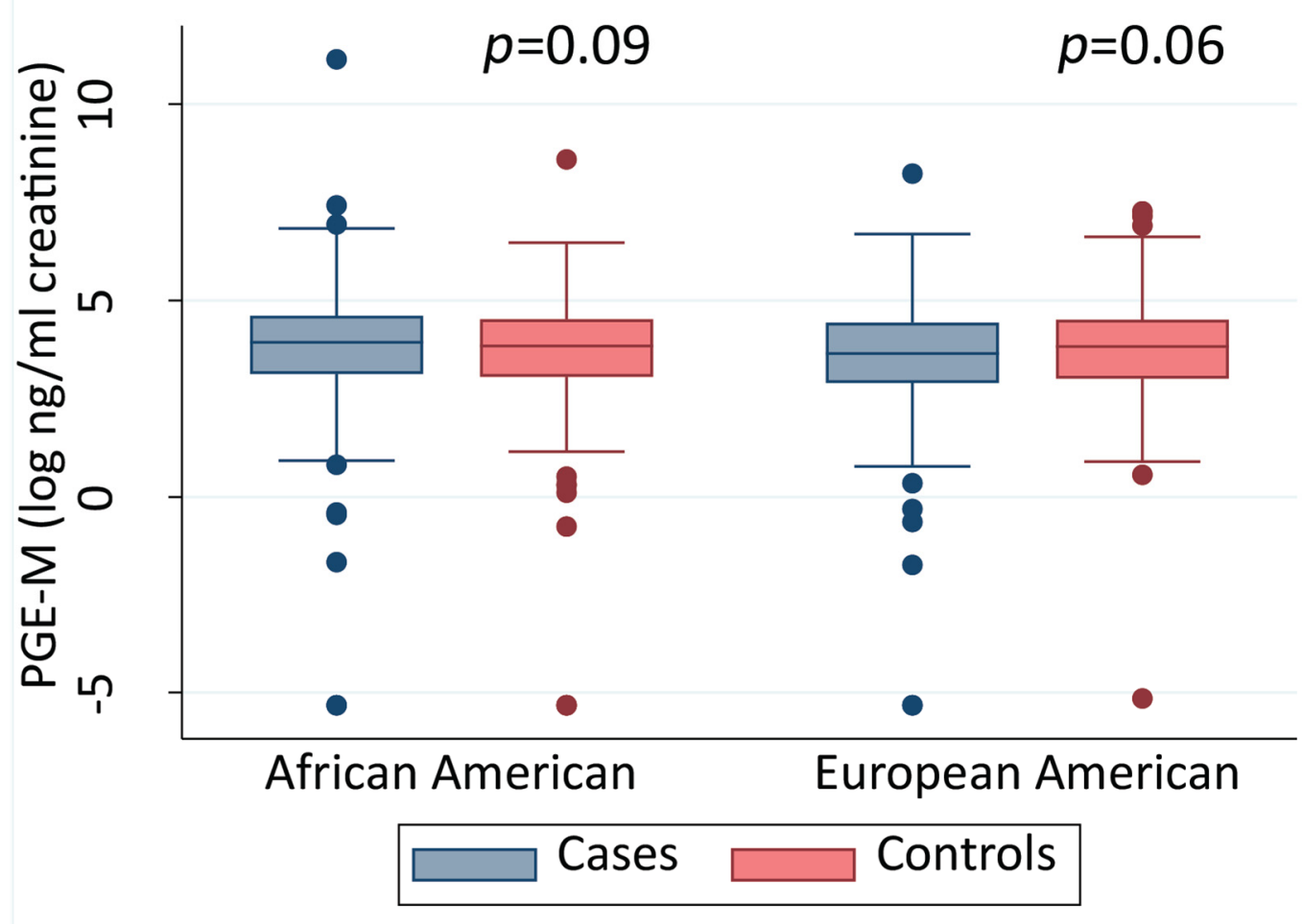

Figure 1. Urinary PGE-M levels in African American and European American men. Urinary PGE-M levels in cases and controls stratified into African American and European American men shown as a continuous measure, stratified by race. A two-sided Mann-Whitney test was applied for statistical significance testing. The error bars represent the $95 \%$ CI.

\subsection{High PGE-M Is Associated with Moderately Decreased Odds of Prostate Cancer in EA Men in the Multivariable Analysis}

We used unconditional logistic regression to further analyze the relationship of PGE$\mathrm{M}$ with a prostate cancer diagnosis and estimated the odds of having prostate cancer when PGE-M is elevated. The adjusted OR for prostate cancer was 0.86 (95\% CI 0.72-1.04) for men with high (>median) PGE-Mcompared to low PGE-M ( $\leq$ median) (Table 1), i.e., no statistically significant association of PGE-M levels with case status in the combined cohort. Because the COX signaling pathway may affect AA and EA prostate cancer patients differently, we stratified the analysis by race/ethnicity. Here, a moderate but 
statistically significant inverse association between high PGE-M and having prostate cancer was observed among EA men (OR $=0.76,95 \%$ CI 0.59-0.99) but not AA men (OR = 1.00, $95 \%$ CI $0.75-1.31)$. Heterogeneity of the odds ratios was further demonstrated using the Breslow-Day test $(p=0.03)$. Our finding for EA men was confirmed when PGE-M was treated as a continuous variable $(\mathrm{OR}=0.88,95 \% \mathrm{CI} 0.79-0.98)$. This observation would suggest a moderate protective rather than a deleterious effect of high PGE-M in association with prostate cancer development in EA men.

Table 1. Association of urinary PGE-M levels with prostate cancer.

\begin{tabular}{|c|c|c|c|c|c|c|c|c|c|c|c|}
\hline \multicolumn{12}{|c|}{ Odds of Case Status $N,(\%)$} \\
\hline & \multicolumn{3}{|c|}{ All Cases } & \multicolumn{3}{|c|}{ African American } & \multicolumn{3}{|c|}{ European American } & \multirow[b]{2}{*}{$\begin{array}{c}\text { P } \\
\text { Hetero- } \\
\text { geneity }\end{array}$} & \multirow[b]{2}{*}{$\begin{array}{l}\text { P Inter- } \\
\text { action }\end{array}$} \\
\hline PGE-M & Control & Case & $\begin{array}{c}\text { OR } \\
(95 \% \text { CI) }\end{array}$ & Control & Case & $\begin{array}{c}\text { OR } \\
(95 \% \text { CI) }\end{array}$ & Control & Case & $\begin{array}{c}\text { OR } \\
(95 \% \text { CI) }\end{array}$ & & \\
\hline$\leq$ Median $^{\mathrm{a}}$ & $499(50)$ & $\begin{array}{l}482 \\
(51)\end{array}$ & Reference & $231(50)$ & $\begin{array}{l}216 \\
(46)\end{array}$ & Reference & $268(50)$ & $\begin{array}{l}266 \\
(56)\end{array}$ & Reference & 0.03 & 0.04 \\
\hline $\begin{array}{c}\text { >Median } \\
\text { Continuous }{ }^{b}\end{array}$ & $499(50)$ & $\begin{array}{l}466 \\
(49)\end{array}$ & $\begin{array}{c}0.86 \\
(0.72-1.04) \\
0.96 \\
(0.89-1.03)\end{array}$ & $234(50)$ & $\begin{array}{l}256 \\
(54)\end{array}$ & $\begin{array}{c}1.0 \\
(0.75-1.31) \\
1.03 \\
(0.93-1.14)\end{array}$ & $265(50)$ & $\begin{array}{l}210 \\
(44)\end{array}$ & $\begin{array}{c}0.76 \\
(0.59-0.99) \\
0.88 \\
(0.79-0.98)\end{array}$ & & \\
\hline
\end{tabular}

Note: column total sums $(N, \%)$ that differ are due to missing data. Bolded data indicate significant associations in the logistic regression analysis. ${ }^{a}$ Median cutoff point is $14.22 \mathrm{ng}$ PGE-M per mg creatinine. ${ }^{\mathrm{b}}$ PGE-M as a continuous, $\log 2$ transformed variable. ${ }^{*}$ Unconditional logistic regression adjusted for age at study entry, BMI $\left(\mathrm{kg} / \mathrm{m}^{2}\right)$, diabetes (no/yes), aspirin (no/yes), education (high school or less, some college, college, professional school), family history of prostate cancer (first-degree relatives, yes/no), self-reported race (not included in stratified analysis), smoking history (never, former, current).

Elevated PGE-M has previously been associated with lung and colon cancer metastasis [4,14], so we investigated the association between PGE-M, aggressive disease, and metastasis. We assigned men with prostate cancer into NCCN risk groups as described under Methods and shown in Table S2. There was no association between high PGE-M (>median vs. $\leq$ median) and the risk score classification for localized disease and metastatic disease, indicating that urinary PGE-M levels do not define intrinsic prostate cancer aggressiveness (Table 2).

Table 2. Association of high urinary PGE-M with national comprehensive cancer network risk (NCCN) score for metastatic prostate cancer.

\begin{tabular}{ccc}
\hline NCCN Risk Score & OR $(\mathbf{9 5} \% \mathbf{C I}){ }^{*}$ & $p$ Value \\
\hline Low & Reference & \\
Intermediate & $0.96(0.65-1.43)$ & 0.85 \\
High/Very High & $1.13(0.71-1.81)$ & 0.60 \\
Regional/Metastatic & $0.93(0.44-1.97)$ & 0.85 \\
\hline
\end{tabular}

Note: * Unconditional logistic regression adjusted for age at study entry, BMI $\left(\mathrm{kg} / \mathrm{m}^{2}\right)$, diabetes (no/yes), aspirin (no/yes), education (high school or less, some college, college, professional school), family history of prostate cancer (first-degree relatives, yes/no), self-reported race, smoking history (never, former, current), treatment $(0=$ none, 1 = surgery, 2 radiation, 3 = hormone, $4=$ combination $)$.

\subsection{PGE-M and Prostate Cancer Mortality}

We next examined if there is an association between PGE-M and survival outcomes in our case population. As of the end of 2018, there have been 246 deaths in our case population, of whom $27 \%$ had a prostate cancer as the recorded primary cause of death $(\mathrm{n}=66)$.

Applying a multivariable-adjusted Cox regression model (Table 3), we report no significant association between PGE-M levels and all-cause mortality among men with prostate cancer in the unstratified analysis when PGE-M levels were coded as both a dichotomized ( $\leq$ median compared to $>$ median) and continuous measure. The observation remained consistent even when our analysis was further stratified by self-reported race. Prostate cancer-specific survival is a key outcome measure for prostate cancer patients. 
Using a multivariable Cox regression model, we found that high PGE-M was not associated with lethal prostate cancer, although the number of prostate cancer deaths was limited (Table 4) (Figure S1 for unadjusted Kaplan-Meier graphs). Similar relationships were observed when we used continuous PGE-M data in the survival analysis (Table 4).

Table 3. Association of urinary PGE-M levels with all-cause mortality among prostate cancer patients.

\begin{tabular}{|c|c|c|c|c|c|c|}
\hline Title & PGE-M & Alive & Dead & HR (95\% CI) & $\operatorname{HR}(95 \% \mathrm{CI})^{\dagger}$ & $\operatorname{HR}(95 \% \mathrm{CI}) *$ \\
\hline \multirow[t]{3}{*}{ All Cases } & $\leq$ Median $^{\text {a }}$ & $376(53)$ & $105(44)$ & Reference & Reference & Reference \\
\hline & $>$ Median & $329(47)$ & $135(56)$ & 1.43 (1.11-1.84) & 1.35 (1.05-1.74) & $1.16(0.89-1.52)$ \\
\hline & Continuous ${ }^{b}$ & & & $1.12(1.02-1.24)$ & $1.09(0.99-1.21)$ & $1.00(0.90-1.12)$ \\
\hline \multirow[t]{3}{*}{ African American } & $\leq$ Median $^{\mathrm{a}}$ & $165(49)$ & $50(37)$ & Reference & Reference & Reference \\
\hline & >Median & $171(51)$ & $84(63)$ & 1.47 (1.04-2.08) & $1.39(0.98-1.96)$ & $1.30(0.91-1.87)$ \\
\hline & Continuous ${ }^{b}$ & & & $1.09(0.96-1.23)$ & $1.07(0.94-1.23)$ & $1.02(0.88-1.17)$ \\
\hline \multirow[t]{3}{*}{ European American } & $\leq$ Median $^{\mathrm{a}}$ & $211(57)$ & $55(52)$ & Reference & Reference & Reference \\
\hline & $>$ Median & $158(43)$ & $51(48)$ & $1.26(0.86-1.84)$ & $1.14(0.78-1.67)$ & $0.97(0.64-1.47)$ \\
\hline & Continuous ${ }^{b}$ & & & $1.12(0.96-1.32)$ & $1.05(0.89-1.24)$ & $0.95(0.80-1.13)$ \\
\hline
\end{tabular}

Note: column total sums $(N, \%)$ that differ are due to missing data. Bolded data indicate significant associations in the Cox regression analysis. ${ }^{a}$ Median cutoff point is $14.22 \mathrm{ng}$ PGE-M per mg creatinine. ${ }^{\mathrm{b}}$ PGE-M as a continuous, $\log 2$ transformed variable. ${ }^{\dagger}$ Unconditional Cox regression adjusted for age at study entry. * Unconditional Cox regression adjusted for age at study entry, BMI $\left(\mathrm{kg} / \mathrm{m}^{2}\right)$, diabetes (no/yes), aspirin (no/yes), education (high school or less, some college, college, professional school), family history of prostate cancer (first-degree relatives, yes/no), self-reported race (not included in stratified analysis), smoking history (never, former, current), treatment $(0=$ none, $1=$ surg, $2=$ radiation, $3=$ hormone, $4=$ combination $)$, disease stage $(1=$ stage I, $2=$ stage IIA and IIB, $3=$ stage III, and $4=$ stage IV), Gleason score $(0=$ Gleason $\leq 7$ and $1=$ Gleason $>7)$.

Table 4. Association of urinary PGE-M levels with prostate cancer-specific mortality among prostate cancer patients.

\begin{tabular}{|c|c|c|c|c|c|c|c|c|c|c|}
\hline Title & PGE-M & Alive & $\begin{array}{c}\text { Death } \\
\text { from } \\
\text { PC }\end{array}$ & $\begin{array}{l}\text { Death } \\
\text { from } \\
\text { Other } \\
\text { Cause }\end{array}$ & $\begin{array}{c}\text { HR } \\
(95 \% \mathrm{CI})\end{array}$ & $\begin{array}{c}\text { HR } \\
(95 \% \text { CI })^{\dagger}\end{array}$ & Alive * & $\begin{array}{l}\text { Death } \\
\text { from } \\
\text { PC * }\end{array}$ & $\begin{array}{l}\text { Death } \\
\text { from } \\
\text { Other } \\
\text { Cause * }\end{array}$ & $\underset{(95 \% \mathrm{CI})}{\text { HR }}$ \\
\hline \multirow[t]{2}{*}{ All Cases } & $\leq$ Median $^{\mathrm{a}}$ & 388 (53) & $28(42)$ & $80(44)$ & Reference & Reference & 375 (53) & $27(42)$ & $78(45)$ & Reference \\
\hline & $\begin{array}{c}>\text { Median } \\
\text { Continuous }^{b}\end{array}$ & 339 (47) & $38(58)$ & $100(56)$ & $\begin{array}{c}1.47 \\
(0.90-2.41) \\
\mathbf{1 . 2 4} \\
(\mathbf{1 . 0 3 - 1 . 5 0 )}\end{array}$ & $\begin{array}{c}1.39 \\
(0.85-2.28) \\
\mathbf{1 . 2 3} \\
\mathbf{( 1 . 0 1 - 1 . 4 9 )}\end{array}$ & $327(47)$ & $38(58)$ & $96(55)$ & $\begin{array}{c}1.46 \\
(0.86-2.46) \\
1.21 \\
(0.97-1.50)\end{array}$ \\
\hline \multirow{2}{*}{$\begin{array}{l}\text { African } \\
\text { American }\end{array}$} & $\leq$ Median $^{\mathrm{a}}$ & $172(49)$ & $15(38)$ & $36(38)$ & Reference & Reference & $165(49)$ & $15(38)$ & $35(37)$ & Reference \\
\hline & $\begin{array}{c}>\text { Median } \\
\text { Continuous }\end{array}$ & $178(51)$ & $25(63)$ & $60(63)$ & $\begin{array}{c}1.43 \\
(0.75-2.70) \\
1.18 \\
(0.94-1.48)\end{array}$ & $\begin{array}{c}1.33 \\
(0.70-2.52) \\
1.17 \\
(0.92-1.50)\end{array}$ & $171(51)$ & $25(62)$ & $59(63)$ & $\begin{array}{c}1.49 \\
(0.75-2.98) \\
1.13 \\
(0.85-1.48)\end{array}$ \\
\hline \multirow{2}{*}{$\begin{array}{l}\text { European } \\
\text { American }\end{array}$} & $\leq$ Median $^{\mathrm{a}}$ & $216(57)$ & $13(50)$ & $44(52)$ & Reference & Reference & $210(57)$ & $12(48)$ & $43(54)$ & Reference \\
\hline & $\begin{array}{c}\text { >Median } \\
\text { Continuous }^{b}\end{array}$ & $161(43)$ & $13(50)$ & $40(48)$ & $\begin{array}{c}1.28 \\
(0.58-2.81) \\
1.27 \\
(0.91-1.78)\end{array}$ & $\begin{array}{c}1.16 \\
(0.53-2.56) \\
1.20 \\
(0.85-1.70)\end{array}$ & $156(43)$ & $13(52)$ & $37(46)$ & $\begin{array}{c}1.30 \\
(0.54-3.14) \\
1.43 \\
(0.95-2.15)\end{array}$ \\
\hline
\end{tabular}

Note: column total sums $(N, \%)$ that differ are due to missing data. Bolded data indicate significant associations in the Cox regression analysis. ${ }^{a}$ Median cutoff point is $14.22 \mathrm{ng}$ PGE-M per mg creatinine. ${ }^{\mathrm{b}}$ PGE-M as a continuous, $\log 2$ transformed variable. ${ }^{\dagger}$ Unconditional Cox regression adjusted for age at study entry. ${ }^{*}$ Unconditional Cox regression adjusted for age at study entry, BMI $\left(\mathrm{kg} / \mathrm{m}^{2}\right)$, diabetes (no/yes), aspirin (no/yes), education (high school or less, some college, college, professional school), family history of prostate cancer (first-degree relatives, yes/no), self-reported race (not included in stratified analysis), smoking history (never, former, current), treatment $(0=$ none, $1=$ surg, $2=$ radiation, $3=$ hormone, $4=$ combination $)$, disease stage $(1=$ stage I, $2=$ stage IIA and IIB, $3=$ stage III, and $4=$ stage IV), Gleason score $(0=$ Gleason $\leq 7$ and $1=$ Gleason $>7)$.

\subsection{Aspirin Use Attenuates the Association between Elevated PGE-M and All-Cause Mortality in Prostate Cancer Patients}

Aspirin has been shown to inhibit PGE-M biosynthesis [22], so we explored the possibility of an interaction between aspirin use and PGE-M on survival. No such interaction was found in the analysis of all-cause survival $(p=0.11)$ (Table 5) but stratification of cases by aspirin use status (yes/no) revealed disparate outcomes. There was a statistically significant association between high PGE-M and all-cause survival in the cases who reported no aspirin use. For the cases who reported using aspirin, there was no significant 
relationship ( $\mathrm{HR}=0.92$ 95\% CI 0.63-1.34). However, when stratified by self-reported race, the association between high PGE-M and all-cause mortality remained significant only in AA men who did not use aspirin ( $\mathrm{HR}=2.04,95 \% \mathrm{CI} 1.23-3.37)$ (Table 5). This finding is mirrored in the analysis of PGE-M as a continuous variable with a positive association with all-cause mortality for non-aspirin users (HR $=1.2795 \%$ CI 1.03-1.57) and no association with all-cause mortality of aspirin users ( $\mathrm{HR}=0.8595 \% 0.70-1.02)$.

Table 5. Association of urinary PGE-M levels with all-cause mortality among men with prostate cancer after stratification by aspirin use.

\begin{tabular}{|c|c|c|c|c|c|c|c|c|c|c|c|c|}
\hline Title & & All C & ses & & rican $A$ & nerican & & & opean & merican & & \\
\hline PGE-M & Alive & Dead & $\begin{array}{c}\text { HR } \\
(95 \% \mathrm{CI})\end{array}$ & Alive & Dead & $\begin{array}{c}\text { HR } \\
(95 \% \text { CI) }\end{array}$ & $\begin{array}{c}\mathbf{P} \\
\text { Hetero- } \\
\text { geneity }\end{array}$ & Alive & Dead & $\begin{array}{c}\text { HR } \\
(95 \% \text { CI) }\end{array}$ & $\begin{array}{l}\text { P Inter- } \\
\text { action } \\
\quad \#\end{array}$ & $\begin{array}{c}\text { P Inter- } \\
\text { action } \\
+\end{array}$ \\
\hline $\begin{array}{c}\leq \text { Median } \\
>\text { Median } \\
\text { Continuous }\end{array}$ & $\begin{array}{l}182 \\
(53) \\
162 \\
(47)\end{array}$ & $\begin{array}{c}62 \\
(50) \\
63 \\
(50)\end{array}$ & $\begin{array}{c}\text { Reference } \\
0.92 \\
(0.63-1.34) \\
0.93 \\
(0.81-1.07)\end{array}$ & $\begin{array}{c}\text { A } \\
61 \\
(43) \\
81 \\
(57)\end{array}$ & $\begin{array}{c}\text { Spirin u } \\
25 \\
(42) \\
34 \\
(58)\end{array}$ & $\begin{array}{l}\text { e } \\
\text { Reference } \\
0.70 \\
(0.40-1.23) \\
0.85 \\
(0.70-1.02)\end{array}$ & 0.04 & $\begin{array}{c}121 \\
(60) \\
81 \\
(40)\end{array}$ & $\begin{array}{c}37 \\
(56) \\
29 \\
(44)\end{array}$ & $\begin{array}{c}\text { Reference } \\
1.05 \\
(0.63-1.75) \\
1.00 \\
(0.81-1.23)\end{array}$ & 0.11 & 0.38 \\
\hline $\begin{array}{c}\leq \text { Median } \\
>\text { Median } \\
\text { Continuous }\end{array}$ & $\begin{array}{l}193 \\
(53) \\
165 \\
(46)\end{array}$ & $\begin{array}{c}43 \\
(38) \\
71 \\
(62)\end{array}$ & $\begin{array}{c}\text { Reference } \\
\mathbf{1 . 5 2} \\
\mathbf{( 1 . 0 3 - 2 . 2 4 )} \\
1.14 \\
(0.96-1.35)\end{array}$ & $\begin{array}{l}\text { No } \\
104 \\
(54) \\
90 \\
(46)\end{array}$ & $\begin{array}{c}\text { aspirin } \\
25 \\
(33) \\
50 \\
(67)\end{array}$ & $\begin{array}{l}\text { se } \\
\text { Reference } \\
2.04 \\
(1.23-3.37) \\
1.27 \\
(1.03-1.57)\end{array}$ & & $\begin{array}{c}89 \\
(54) \\
75 \\
(46)\end{array}$ & $\begin{array}{c}18 \\
(46) \\
21 \\
(54)\end{array}$ & $\begin{array}{c}\text { Reference } \\
0.99 \\
(0.48-2.07) \\
0.91 \\
(0.67-1.22)\end{array}$ & & \\
\hline
\end{tabular}

Note: Bolded data indicate significant associations in the Cox regression analysis. ${ }^{\text {a }}$ median cutoff point is $14.22 \mathrm{ng}$ PGE-M per mg creatinine. b PGE-M as a continuous, log2 transformed variable. ${ }^{*}$ Unconditional Cox regression adjusted for age at study entry, BMI $\left(\mathrm{kg} / \mathrm{m}^{2}\right)$, diabetes (no/yes), education (high school or less, some college, college, professional school), family history of prostate cancer (first-degree relatives, yes $/$ no), self-reported race (not included in stratified analysis), smoking history (never, former, current), treatment $(0=$ none, $1=$ surgery, $2=$ radiation, $3=$ hormone, $4=$ combination), disease stage ( $1=$ stage I, $2=$ stage IIA and IIB, $3=$ stage III, $4=$ stage IV), Gleason score $(0=$ Gleason $\leq 7$ and $1=$ Gleason $>7)$ and stratified by aspirin (no/yes). \# Test for interaction between level of PGE-M and aspirin use.

+ Test for interaction between self-reported race and aspirin use.

\section{Discussion}

In this retrospective case-control study, we report no difference in urinary PGE-M levels between cases and controls. We observed no association between elevated PGE-M and metastatic disease nor prostate-cancer-specific mortality. Of note, however, we report a significant association between elevated PGE-M and increased all-cause mortality in AA men with prostate cancer when they did not take aspirin. This association was not observed in AA men who had reported aspirin use, suggesting that aspirin may reduce all-cause mortality for AA men with prostate cancer. This is potentially of clinical importance as these results support a role for aspirin as a chemopreventive agent against mortality in men with prostate cancer. However, the hypothesis that the chemopreventive mechanism of action of aspirin is via PGE-M in prostate cancer is not supported by this study, as we did not find that aspirin use inhibited PGE-M formation in AA men with prostate cancer (Table S3).

Dysregulated COX signaling and PGE2 production have been observed across many tumor types [6,30-33]. Elevated PGE-M, reflecting in vivo PGE2 biosynthesis, has been associated with cancers of the colon [14,22,34], pancreas [16], stomach [17,35], post-menopausal breast [15,36], and lung [4]. However, this relationship was not observed in ovarian cancer [18], and our results now indicate very little evidence for elevated PGE-M playing a role in prostate cancer.

The finding of moderately decreased odds of prostate cancer in EA men with elevated PGE-M was unexpected given what is already known about elevated PGE-M being associated with cancer development at other organ sites such as the colon (summarized in Table S4). We do not have an answer as to why this may be happening, but what it does suggest is that COX signaling may be working differently in prostate cancer when 
compared to other cancer sites, with PGE2 signaling not being an oncogenic driver of the disease.

Chronic inflammation has been described as a prostate cancer risk factor that is associated with aggressive disease [2,3]. Epidemiological studies have reported protective effects of aspirin against aggressive disease and adverse outcomes in high-risk groups with prostate cancer $[23,24]$. Identifying PGE-M as a novel marker of aggressive disease would have importance for high-risk groups such as men of African descent who experience a disproportionately high burden of prostate cancer lethality. However, we did not find evidence for such a mechanism.

The lack of a robust PGE-M inhibition in both cases and controls who reported aspirin use in our study was surprising. Many studies have now demonstrated how aspirin use, at various doses, lowers urinary PGE-M levels [34,37]. However, Drew et al. reported approximately $20-25 \%$ of participants in the ASPIRED study who were randomized to 81 or $325 \mathrm{mg}$ /day of aspirin experienced no inhibition or even an increase in PGE-M from baseline despite demonstrating a strong inhibition of urinary thromboxane B2 [22]. This finding is consistent with our data, where in a previous study, using the same cohort of participants, we reported strong thromboxane B2 inhibition in aspirin users across both cases and controls [38]. This suggests that the participants in our study are not nonresponders to aspirin, but rather, aspirin use mechanistically is not targeting PGE-M in these men. It may also suggest that higher doses of aspirin are required in some men to achieve significant levels of PGE-M inhibition. Our lack of dose information prevents us from further investigating this phenomenon.

Our study has certain limitations. First, the case-control study design is retrospective, so it remains unknown if elevated PGE-M is protective against prostate cancer development in EA men. Second, we lack aspirin dose and dose compliance information, which prevents us from presenting data on the importance of aspirin dose in preventing all-cause mortality in AA men. However, the ASPIRED and AFPPS trials observed similar levels of PGE-M inhibition when either $81 \mathrm{mg} /$ day or $325 \mathrm{mg} /$ day doses were administered [22,37]. We also lack detailed data on the frequency of aspirin use, which would potentially provide more accurate estimates of PGE-M inhibition following aspirin use.

A major strength of this case-control study is the participant diversity, with very similar numbers of AA and EA participants. With $50 \%$ of cases and $47 \%$ of controls selfreporting as $\mathrm{AA}$, we have a unique opportunity to examine biological factors that may promote cancer differently between population groups.

\section{Conclusions}

In summary, we evaluated associations between PGE-M levels and prostate cancer in a case-control study. We found no association between urinary PGE-M and aggressive prostate cancer. An association between elevated PGE-M and all-cause mortality in nonaspirin AA users reinforces the potential benefit of aspirin for the prevention of lethal prostate cancer, but the evidence does not support the mechanism of action to be via PGE-M inhibition. A prospective study is needed to confirm these findings.

Supplementary Materials: The following are available online at https: / www.mdpi.com/article/ 10.3390 / cancers13164073/s1, Supplementary Methods, Table S1: Characteristics of cases and population controls in the NCI-Maryland Prostate Cancer Case-Control Study, Table S2: Men with prostate cancer by urinary PGE-M level and national comprehensive cancer network risk score, Table S3: Association of regular aspirin use with urinary PGEM levels in cases and controls, Table S4: Association of PGE-M and cancer risk from published literature, Figure S1: High urinary PGE-M levels are not significantly associated with increased prostate cancer-specific mortality.

Author Contributions: M.K.: conceptualization; investigation; data curation; methodology; formal analysis; writing—original draft; writing—review and editing, G.L.M.: methodology, T.Z.M.: conceptualization; writing - review and editing, T.H.D.: data curation; project administration, W.T.: supervision; writing-review and editing, C.J.S.: writing-review and editing, F.B.: project administration, C.A.L.: methodology; writing-review and editing, C.Y.: writing-review and editing, 
M.B.C.: methodology; writing-review and editing, S.A.; conceptualization; methodology; funding acquisition; resources; writing - review and editing; supervision. All authors have read and agreed to the published version of the manuscript.

Funding: This research was funded by the DoD award W81XWH1810588 (to S.A. and C.Y.) and the Intramural Research Program of the NIH, National Cancer Institute (NCI), Center for Cancer Research and Division of Cancer Epidemiology and Genetics; Maeve Kiely is supported by the NCI Cancer Prevention Fellowship program.

Institutional Review Board Statement: The study was conducted according to the guidelines of the Declaration of Helsinki and approved by the Institutional Review Board of NCI (protocol \#05-C-N021) and the University of Maryland (protocol \#0298229).

Informed Consent Statement: Informed consent was obtained from all subjects involved in the study.

Data Availability Statement: The data underlying this article will be shared upon reasonable request to the corresponding author.

Acknowledgments: We would like to thank the personnel at the University of Maryland and the Baltimore Veterans Administration Hospital for their contributions to the recruitment of subjects. We would also like to thank the subjects who contributed their time and biospecimens to make the NCI-Maryland study possible. Graphical abstract was created with BioRender.com.

Conflicts of Interest: The authors declare no conflict of interest. The funders had no role in the design of the study; in the collection, analyses, or interpretation of data; in the writing of the manuscript, or in the decision to publish the results.

\section{References}

1. Tang, W.; Wallace, T.A.; Yi, M.; Magi-Galluzzi, C.; Dorsey, T.H.; Onabajo, O.O.; Obajemu, A.; Jordan, S.V.; Loffredo, C.A.; Stephens, R.M.; et al. IFNL4-DeltaG Allele Is Associated with an Interferon Signature in Tumors and Survival of African-American Men with Prostate Cancer. Clin. Cancer Res. 2018, 24, 5471-5481. [CrossRef]

2. Gurel, B.; Lucia, M.S.; Thompson, I.M., Jr.; Goodman, P.J.; Tangen, C.M.; Kristal, A.R.; Parnes, H.L.; Hoque, A.; Lippman, S.M.; Sutcliffe, S.; et al. Chronic Inflammation in Benign Prostate Tissue is Associated with High-Grade Prostate Cancer in the Placebo Arm of the Prostate Cancer Prevention Trial. Cancer Epidemiol. Biomark. Prev. 2014, 23, 847-856. [CrossRef] [PubMed]

3. Klink, J.C.; Banez, L.L.; Gerber, L.; Lark, A.; Vollmer, R.T.; Freedland, S.J. Intratumoral Inflammation is Associated with More Aggressive Prostate Cancer. World J. Urol. 2013, 31, 1497-1503. [CrossRef] [PubMed]

4. Morris, P.G.; Zhou, X.K.; Milne, G.L.; Goldstein, D.; Hawks, L.C.; Dang, C.T.; Modi, S.; Fornier, M.N.; Hudis, C.A.; Dannenberg, A.J. Increased Levels of Urinary PGE-M, a Biomarker of Inflammation, Occur in Association with Obesity, Aging, and lung Metastases in Patients with Breast Cancer. Cancer Prev. Res. 2013, 6, 428-436. [CrossRef] [PubMed]

5. Richardsen, E.; Uglehus, R.D.; Due, J.; Busch, C.; Busund, L.-T. COX-2 is Overexpressed in Primary Prostate Cancer with Metastatic Potential and may Predict Survival. A Comparison Study between COX-2, TGF- $\beta$, IL-10 and Ki67. Cancer Epidemiol. 2010, 34, 316-322. [CrossRef]

6. Garg, R.; Blando, J.M.; Perez, C.J.; Lal, P.; Feldman, M.D.; Smyth, E.M.; Ricciotti, E.; Grosser, T.; Benavides, F.; Kazanietz, M.G. COX-2 Mediates pro-Tumorigenic Effects of PKC $\varepsilon$ in Prostate Cancer. Oncogene 2018, 37, 4735-4749. [CrossRef]

7. Ko, C.; Lan, S.; Lu, Y.; Cheng, T.; Lai, P.; Tsai, C.; Hsu, T.; Lin, H.; Shyu, H.; Wu, S. Inhibition of Cyclooxygenase-2-Mediated Matriptase Activation Contributes to the Suppression of Prostate Cancer Cell Motility and Metastasis. Oncogene 2017, 36, 4597-4609. [CrossRef]

8. Mason, M.D.; Clarke, N.W.; James, N.D.; Dearnaley, D.P.; Spears, M.R.; Ritchie, A.W.S.; Attard, G.; Cross, W.; Jones, R.J.; Parker, C.C.; et al. Adding Celecoxib With or Without Zoledronic Acid for Hormone-Naïve Prostate Cancer: Long-Term Survival Results From an Adaptive, Multiarm, Multistage, Platform, Randomized Controlled Trial. J. Clin. Oncol. 2017, 35, 1530-1541. [CrossRef]

9. Wang, D.; Dubois, R.N. The role of COX-2 in Intestinal Inflammation and Colorectal Cancer. Oncogene 2010, 29, 781-788. [CrossRef]

10. Wang, D.; Fu, L.; Sun, H.; Guo, L.; DuBois, R.N. Prostaglandin E2 Promotes Colorectal Cancer Stem Cell Expansion and Metastasis in Mice. Gastroenterology 2015, 149, 1884-1895.e4. [CrossRef]

11. Cen, B.; Lang, J.D.; Du, Y.; Wei, J.; Xiong, Y.; Bradley, N.; Wang, D.; DuBois, R.N. Prostaglandin E2 Induces miR675-5p to Promote Colorectal Tumor Metastasis via Modulation of p53 Expression. Gastroenterology 2020, 158, 971-984. [CrossRef] [PubMed]

12. Catella, F.; Nowak, J.; Fitzgerald, G.A. Measurement of Renal and Non-Renal Eicosanoid Synthesis. Am. J. Med. 1986, 81, 23-29. [CrossRef]

13. Frölich, J.; Wilson, T.W.; Sweetman, B.J.; Smigel, M.; Nies, A.S.; Carr, K.; Watson, J.T.; Oates, J.A. Urinary prostaglandins. Identification and Origin. J. Clin. Investig. 1975, 55, 763-770. [CrossRef] [PubMed] 
14. Johnson, J.C.; Schmidt, C.R.; Shrubsole, M.J.; Billheimer, D.D.; Joshi, P.R.; Morrow, J.D.; Heslin, M.J.; Washington, M.K.; Ness, R.M.; Zheng, W. Urine PGE-M: A Metabolite of Prostaglandin E2 as a Potential Biomarker of Advanced Colorectal Neoplasia. Clin. Gastroenterol. Hepatol. 2006, 4, 1358-1365. [CrossRef]

15. Kim, S.; Campbell, J.; Yoo, W.; Taylor, J.A.; Sandler, D.P. Systemic Levels of Estrogens and PGE2 Synthesis in Relation to Postmenopausal Breast Cancer Risk. Cancer Epidemiol. Prev. Biomark. 2017, 26, 383-388. [CrossRef]

16. Zhao, J.; Wang, J.; Du, J.; Xu, H.; Zhang, W.; Ni, Q.-X.; Yu, H.; Risch, H.A.; Gao, Y.-T.; Gao, Y. Urinary Prostaglandin E 2 Metabolite and Pancreatic Cancer Risk: Case-Control Study in Urban Shanghai. PLoS ONE 2015, 10, e0118004. [CrossRef] [PubMed]

17. Wang, T.; Cai, H.; Zheng, W.; Michel, A.; Pawlita, M.; Milne, G.; Xiang, Y.-B.; Gao, Y.-T.; Li, H.-L.; Rothman, N. A Prospective Study of Urinary Prostaglandin E2 Metabolite, Helicobacter Pylori Antibodies, and Gastric Cancer Risk. Clin. Infect. Dis. 2017, 64, 1380-1386. [CrossRef] [PubMed]

18. Barnard, M.E.; Beeghly-Fadiel, A.; Milne, G.L.; Akam, E.Y.; Chan, A.T.; Eliassen, A.H.; Rosner, B.A.; Shu, X.-O.; Terry, K.L.; Xiang, Y.-B. Urinary PGE-M Levels and Risk of Ovarian Cancer. Cancer Epidemiol. Prev. Biomark. 2019, 28, 1845-1852. [CrossRef]

19. De Marzo, A.M.; Platz, E.A.; Sutcliffe, S.; Xu, J.; Gronberg, H.; Drake, C.G.; Nakai, Y.; Isaacs, W.B.; Nelson, W.G. Inflammation in Prostate Carcinogenesis. Nat. Rev. Cancer 2007, 7, 256-269. [CrossRef]

20. Bibbins-Domingo, K. Aspirin Use for the Primary Prevention of Cardiovascular Disease and Colorectal Cancer: US Preventive Services Task Force recommendation statement. Ann. Intern. Med. 2016, 164, 836-845. [CrossRef] [PubMed]

21. Dehmer, S.P.; Maciosek, M.V.; Flottemesch, T.J.; LaFrance, A.B.; Whitlock, E.P. Aspirin for the Primary Prevention of Cardiovascular Disease and Colorectal Cancer: A Decision Analysis for the US Preventive Services Task Force. Ann. Intern. Med. 2016, 164, 777-786. [CrossRef]

22. Drew, D.A.; Schuck, M.M.; Magicheva-Gupta, M.V.; Stewart, K.O.; Gilpin, K.K.; Miller, P.; Parziale, M.P.; Pond, E.N.; Takacsi-Nagy, O.; Zerjav, D.C. Effect of Low-Dose and Standard-Dose Aspirin on PGE2 Biosynthesis Among Individuals with Colorectal Adenomas: A Randomized Clinical Trial. Cancer Prev. Res. 2020, 13, 877-888. [CrossRef]

23. Tang, W.; Fowke, J.H.; Hurwitz, L.M.; Steinwandel, M.; Blot, W.J.; Ambs, S. Aspirin Use and Prostate Cancer among AfricanAmerican Men in the Southern Community Cohort Study. Cancer Epidemiol. Prev. Biomark. 2021, 30, 539-544. [CrossRef] [PubMed]

24. Smith, C.J.; Dorsey, T.H.; Tang, W.; Jordan, S.V.; Loffredo, C.A.; Ambs, S. Aspirin Use Reduces the Risk of Aggressive Prostate Cancer and Disease Recurrence in African-American Men. Cancer Epidemiol. Prev. Biomark. 2017, 26, 845-853. [CrossRef]

25. Downer, M.K.; Allard, C.B.; Preston, M.A.; Gaziano, J.M.; Stampfer, M.J.; Mucci, L.A.; Batista, J.L. Regular Aspirin Use and the Risk of Lethal Prostate Cancer in the Physicians' Health Study. Eur. Urol. 2017, 72, 821-827. [CrossRef]

26. Hurwitz, L.M.; Joshu, C.E.; Barber, J.R.; Prizment, A.E.; Vitolins, M.Z.; Jones, M.R.; Folsom, A.R.; Han, M.; Platz, E.A. Aspirin and Non-Aspirin NSAID Use and Prostate Cancer Incidence, Mortality, and Case Fatality in the Atherosclerosis Risk in Communities Study. Cancer Epidemiol Biomark. Prev. 2019, 28, 563-569. [CrossRef]

27. Minas, T.Z.; Tang, W.; Smith, C.J.; Onabajo, O.O.; Obajemu, A.; Dorsey, T.H.; Jordan, S.V.; Obadi, O.M.; Ryan, B.M.; ProkuninaOlsson, L.; et al. IFNL4-DeltaG is Associated with Prostate Cancer Among men at Increased Risk of Sexually Transmitted Infections. Commun. Biol. 2018, 1, 191. [CrossRef] [PubMed]

28. Murphey, L.J.; Williams, M.K.; Sanchez, S.C.; Byrne, L.M.; Csiki, I.; Oates, J.A.; Johnson, D.H.; Morrow, J.D. Quantification of the Major Urinary Metabolite of PGE2 by a Liquid Chromatographic/Mass Spectrometric Assay: Determination of CyclooxygenaseSpecific PGE2 Synthesis in Healthy Humans and those with Lung Cancer. Anal. Biochem. 2004, 334, 266-275. [CrossRef]

29. National Comprehensive Cancer Network. The NCCN Clinical Practice Guidelines in Oncology for Prostate Cancer, V4. 2019. Available online: https:/ / www.nccn.org/professionals/physician_gls/default.aspx\#prostate (accessed on 16 November 2020).

30. Ogino, S.; Kirkner, G.J.; Nosho, K.; Irahara, N.; Kure, S.; Shima, K.; Hazra, A.; Chan, A.T.; Dehari, R.; Giovannucci, E.L. Cyclooxygenase-2 Expression is an Independent Predictor of Poor Prognosis in Colon Cancer. Clin. Cancer Res. 2008, 14, 8221-8227. [CrossRef]

31. Farooqui, M.; Li, Y.; Rogers, T.; Poonawala, T.; Griffin, R.; Song, C.; Gupta, K. COX-2 Inhibitor Celecoxib Prevents Chronic Morphine-Induced Promotion of Angiogenesis, Tumour Growth, Metastasis and Mortality, without Compromising Analgesia. Br. J. Cancer 2007, 97, 1523-1531. [CrossRef] [PubMed]

32. Chan, A.T.; Ogino, S.; Fuchs, C.S. Aspirin and the Risk of Colorectal Cancer in Relation to the Expression of COX-2. N. Engl. J. Med. 2007, 356, 2131-2142. [CrossRef] [PubMed]

33. Connolly, E.M.; Harmey, J.H.; O'Grady, T.; Foley, D.; Roche-Nagle, G.; Kay, E.; Bouchier-Hayes, D.J. Cyclo-Oxygenase Inhibition Reduces Tumour Growth and Metastasis in an Orthotopic Model of Breast Cancer. Br. J. Cancer 2002, 87, 231-237. [CrossRef] [PubMed]

34. Bezawada, N.; Song, M.; Wu, K.; Mehta, R.S.; Milne, G.L.; Ogino, S.; Fuchs, C.S.; Giovannucci, E.L.; Chan, A.T. Urinary PGE-M Levels are Associated with Risk of Colorectal Adenomas and Chemopreventive Response to Anti-Inflammatory Drugs. Cancer Prev. Res. 2014, 7, 758-765. [CrossRef]

35. Dong, L.M.; Shu, X.-O.; Gao, Y.-T.; Milne, G.; Ji, B.-T.; Yang, G.; Li, H.-L.; Rothman, N.; Zheng, W.; Chow, W.-H. Urinary Prostaglandin E2 Metabolite and Gastric Cancer Risk in the Shanghai Women's Health Study. Cancer Epidemiol. Prev. Biomark. 2009, 18, 3075-3078. [CrossRef] [PubMed]

36. Cui, Y.; Shu, X.-O.; Gao, Y.-T.; Cai, Q.; Ji, B.-T.; Li, H.-L.; Rothman, N.; Wu, J.; Yang, G.; Xiang, Y.-B. Urinary Prostaglandin E2 Metabolite and Breast Cancer Risk. Cancer Epidemiol. Prev. Biomark. 2014, 23, 2866-2873. [CrossRef] 
37. Fedirko, V.; Bradshaw, P.T.; Figueiredo, J.C.; Sandler, R.S.; Barry, E.L.; Ahnen, D.J.; Milne, G.L.; Bresalier, R.S.; Baron, J.A. Urinary Metabolites of Prostanoids and Risk of Recurrent Colorectal Adenomas in the Aspirin/Folate Polyp Prevention Study (AFPPS). Cancer Prev. Res. 2015, 8, 1061-1068. [CrossRef]

38. Kiely, M.; Milne, G.L.; Minas, T.Z.; Dorsey, T.H.; Tang, W.; Smith, C.J.; Baker, F.; Loffredo, C.A.; Yates, C.; Cook, M.B. Urinary Thromboxane B2 and Lethal Prostate Cancer in African American Men. JNCI J. Natl. Cancer Inst. 2021. [CrossRef] 